Article

\title{
Sensitivity Factors Analysis on the Compressive Strength and Flexural Strength of Recycled Aggregate Infill Wall Materials
}

\author{
Zongping Chen ${ }^{1,2}, *$, Yaqi Zhang ${ }^{1}$, Jianjia Chen ${ }^{1}$ and Jie Fan ${ }^{1}$ if \\ 1 College of Civil Engineering and Architecture, Guangxi University, Nanning 530004, China; \\ Yaqi798@163.com (Y.Z.); Jianjiaata@163.com (J.C.); jfan1988@163.com (J.F.) \\ 2 Key Laboratory of Disaster Prevention and Structure Safety of Chinese Ministry of Education, \\ Guangxi University, Nanning 530004, China \\ * Correspondence: zpchen@gxu.edu.cn; Tel.: +86-138-7880-6048
}

Received: 17 May 2018; Accepted: 28 June 2018; Published: 5 July 2018

\begin{abstract}
This paper describes an experimental research study designed to evaluate the feasibility of usage of the crushed clay brick and concrete block as fine aggregate raw materials producing recycled aggregate infill wall materials. To better understand the influences of various factors, an investigation was carried out with 96 specimens made by regenerated brick granule and concrete block. The regenerated brick granule content (regenerated brick granule and concrete granule proportion), water-cement ratio, aggregate-cement ratio, lime content and aggregate replacement rate were considered in an orthogonal experimental design method (DOE method) involving five factors and four factor levels. The mechanical properties of the recycled aggregate infill wall materials (RAIW) between each factor and level were evaluated by compressive strength, flexural strength and the flexural-compressive ratio. The empirical relationship among mechanical properties and factors of recycled aggregate infill wall materials was proposed by using multivariate regression analysis. The results showed that the water-cement ratio was $0.7-0.8$ which is especially effective for improving the compressive strength and flexural strength of recycled aggregate infill wall materials, and the aggregate-cement ratio was the most significant factor in the flexural-compressive ratio.
\end{abstract}

Keywords: recycled aggregate infill wall materials; orthogonal test; compressive strength; flexural strength; water-cement ratio

\section{Introduction}

As the population of the world grows and living conditions improve, the number of construction and demolition activities around the world is increasing every year. It has been reported that the construction sector generated 1134 million tons of waste in 2014 in China [1]. The cyclic utilization of construction and demolition waste that produces recycled concrete (RC) and recycled aggregate infill wall materials (RAIW) can allow the sustainable development of the construction industry with good social, economic and environmental benefits. Construction and demolition waste is the primary solid waste and is generally composed of crushed clay brick, sand, concrete block, dust, mud and timber. The development and utilization of this construction waste is imminent; however, few existing studies of crushed clay brick and concrete blocks and analyses of the influential factors exist. This has become a prominent social and environmental problem recently.

In order to study the main influential factors, the aggregate replacement rate, recycled coarse aggregate specification, raw concrete strength and aggregate flaw have been evaluated in regard to mechanical properties of the elastic modulus, compressive strength, splitting tensile strength, flexural strength and the flexural-compressive ratio. A series of factors affecting the recycled aggregate concrete 
was analyzed, which including the substitution rate [2-8], the interfacial transition zone [9-11], the aggregate particle size [12,13], the type of aggregates [7,8,14-16] and aggregate combination [16-20]. A series of tests were conducted to determine the optimum mix proportion of recycled concrete made from the crushed brick and concrete block.

Numerous studies about recycled aggregate concrete (RAC) have been conducted, most of which have focused on the influence of the substitution rate of the recycled aggregate (RA) on the mechanical properties of the concrete. Compared to conventional aggregate concrete (CA), it has been reported that the compressive strength of RAC does not obviously decline at levels below a ratio of $30 \%$ ratio, but it is lower than that of the level at $100 \%[17,21]$ which is different from other observations. M. Etxeberria et al. [4] found that the mechanical properties of four mix proportions in concrete were designed by $0 \%, 25 \%, 50 \%$ and $100 \%$ substitution levels of recycled coarse aggregate (RCA), respectively. The results showed that the 28-day compressive strength of the RAC with $100 \%$ of RCA decreased by $20-25 \%$ compared with the conventional concrete at the same water-cement ratio level. Moreover, the adhered mortar and the strength of the recycled aggregate (RC) effectively influenced the medium-high strength concrete made by the RC. A.M. Wagih et al. noticed that there was no significant degradation of the mechanical properties of concrete when the substitution rate varied from 0.25 to 0.50 . In addition, there was no significant effect on the structure of concrete at the level of $25 \%$ replacement level of natural coarse aggregate (NCA) by recycled coarse aggregate (RCA) [6]. Jesus Suarez Gonzalez et al. [15] found that the maximum reduction of compressive strength at $100 \%$ substitution level with ceramic brick aggregates rose to $28 \%$. Most of these investigations were aimed at the substitution rate of the RA; however, research about the influencing factors on the RAIW mechanical properties has been limited.

The particle size and type of the recycled aggregate have effects on the mechanical properties of the RAC. Miguel C.S. Nepomuceno et al. [7] reported that the substitution rate of the natural coarse aggregate (NCA) replaced by the industrial brick waste (RCA) was up to $75 \%$ in absolute volume fraction. The hardened concrete was evaluated in regard to its mechanical properties-compressive strength, flexural strength, tensile splitting strength and density. The results showed that the feasibility of using ceramic as the coarse aggregate is high. F. Debied and S. Kenai [8] examined the feasibility of producing new concrete with crushed brick as coarse and fine aggregate, considering $25 \%, 50 \%$ and $75 \%, 100 \%$ replacement rates of fine and coarse aggregate by the crushed brick, respectively. The results and mechanical performances were evaluated by the water absorption, water permeability, shrinkage, compressive strength, flexural strength and modulus of elasticity. The authors found that the compressive strength at 28 days decreased with the replacement rate.

Chi-Sun Poon et al. [16] evaluated the properties of concrete blocks made with low-grade RA They determined (i) the compressive strength of specimens with $100 \%$ natural fine aggregate content in the concrete. (ii) With an aggregate-cement ratio of 10:1, the 14 days drying shrinkage value of specimens at the $<50 \%$ particle fine aggregate substitution level satisfied the requirement $(0.06 \%)$. It was also indicated that when the recycled fine aggregate content or aggregate-cement ratio decreases, the drying shrinkage value of the concrete block also decreases. (iii) Due to the higher mud content in RFA, the compressive strength reduction level decreases after exposure to high temperatures, which can be explained by the formation of a new crystalline phase: calcium aluminum. Ngoc Kien et al. [17] considered the replacement percentage of coarse aggregate including all particle sizes in the aggregate combined with all particle sizes of NA. The results showed that (i) the compressive strength of the concrete made by the new method could be increased up to $50 \%$ and the amount of RA in concrete was $5.3 \%$ higher than the $30 \%$ of RA that is contained in concrete made by conventional methods. (ii) The splitting tensile strength improved by $2-5 \%$ compared to the conventional combination. (iii) The modulus of elasticity improved by $20 \%$ compared with the conventional combination, and the Poisson's ratio was 0.2 with $30 \%$ RA, which satisfies the requirement. (iv) With RAC substitutions of $30 \%, 50 \%$ and $70 \%$, it was observed that the peak strain of RAC increased by $10 \%$ in the stress-strain curve.

In addition, the qualities of the mortars, the interfacial transition zone (ITZ) and the adhered mortars of recycled aggregate have effects on the recycled aggregate concrete's properties Some 
authors have conducted similar studies [9-11]. J.S. Ryu [9] observed that at low water-cement ratios, the strength of the RAC depends on the effect of the old ITZ, while at higher water-cement ratios, the strength of the RAC is determined by the water-cement ratio. Moreover, Zhen Hua Duan et al. [10] studied the effects of recycled aggregates different amounts of old adhered mortars on the mechanical performance of the RAC. Due to the adherence of the original cement mortars on the surface of the aggregate, the bonding between the old aggregate block and the new cement could be improved. It has been indicated that the ITZ would improve because of the rough surface of the RA. I.F. Saez del Bosque et al. [11] investigated the properties of various RA/paste ITZ in concrete and revealed that the elastic modulus of the ITZ depends on the relative contents of the various constituent materials contained in the recycled aggregate.

Currently, there is a demand for experiments to be conducted to obtain a reasonable mix ratio to attain the expected requirement strength of RAIW made of recycled crushed clay brick and concrete block. Some scholars have conducted in-depth studies on recycled aggregate concrete from different aspects. Zhao Xiao et al. [19] evaluated the feasibility of producing non-structural partition wall blocks with crushed clay brick aggregates. It was observed that the combination of different types of fine aggregates allowed better compressive strength to be obtained, and the flexural strength reached its maximum at a level of $75 \%$ of crushed clay fine aggregates. Due to fine particles filling the voids and diminishing the porosity of the concrete the compressive strength enhanced. This is similar to a previous review of the literature (Poon and Chan, et al.) [20]. It can be concluded the feasibility of using the crushed clay brick derived from earthquakes as coarse and fine aggregates in the production of non-structural wall block is high when the percentage of coarse clay aggregates in concrete is no more than $25 \%$. Suvash Chandra Pual et al. [22] studied the properties of medium range (25-30 Mpa) structural strength concrete produced by normal and recycled brick aggregates. It was shown that (i) the water-cement ratio influencing the compressive strength of brick aggregate concrete increases with age. (ii) Normal brick aggregate has a lower elastic modulus than recycled brick aggregate concrete. (iii) The compressive strength is proportional to abrasion. Refs. [23,24] analyzed recycled aggregate with physical and chemical tests and evaluated the durability of carbonation resistance and chloride ion resistance. It was observed that the RA usage has an effect on the quality of the hardened concrete in regard to its durability.

From the previous analysis, it can be summarized that grasping the effects of the different combinations of the materials' characteristics on the mechanical properties of concrete is necessary. This paper mainly studied the mechanical properties of recycled aggregate infill wall materials produced by the demolition and construction waste. An existing literature review suggested that the mechanical properties of the concrete are the main concerns when testing the recycled aggregate concrete. Mixture ratio design is an important part of the application of RAIW, so studying the which mixture ratios are feasible is essential. However, there are many factors that affect the recycled infill wall material, and the relationship between various factors is complex and difficult to determine through experience. Therefore a sensitivity factors analysis on mechanical perporties of RAIW through experiments is necessary. Five main factors, including the brick-concrete ratio, the water-cement ratio, the cement-aggregate ratio, the lime powder content and the replacement rate of the recycled aggregate were considered in this paper. An orthogonal experiment was conducted with four levels and 16 groups of specimens were, giving 96 specimens in total. The failure mode was revealed, and the effects of various factors were analyzed, and a reasonable mixture ratio is proposed. This can provide other researchers with a reference and facilitate the application of RAIW. Thus, it is of great theoretical significance and engineering application value to study the reasonable mixture ratio of recycled infill wall materials. 


\section{Experimental Program}

\subsection{Materials}

A brief description of the constituent materials used in this investigation is given in the following text. Ordinary Portland cement of 32.5 grade and city water were used, and lime powder was added to the mixture in this study. The natural fine aggregate was chosen from the continuous grading river sand. The recycled fine aggregate was obtained from a school building renovation that produced construction waste with a maximum particle size of less than $4.75 \mathrm{~mm}$ after crushing and sieving. The physical properties of the raw materials of recycled and natural aggregate are shown in Table 1.

Table 1. Physical properties of recycled aggregate and natural aggregate.

\begin{tabular}{|c|c|c|c|c|c|c|}
\hline Type & Brick and Concrete Ratio $(b / c)$ & Apparent Density $\left(\mathrm{kg} / \mathrm{m}^{3}\right)$ & Bulk Density $\left(\mathrm{kg} / \mathrm{m}^{3}\right)$ & Porosity (\%) & Mud Content (\%) & Water Absorption (\%) \\
\hline NFA & - & 2610.0 & 1290.0 & 50.5 & - & 4.3 \\
\hline RFA-1 & 1:0 & 2350.0 & 1159.0 & 55.5 & 13.9 & 41.2 \\
\hline RFA-2 & $2: 1$ & 2372.5 & 1224.0 & 51.0 & 4.4 & 35.3 \\
\hline RFA-4 & $0: 1$ & 2469.5 & 1322.5 & 46.5 & 9.2 & 31.3 \\
\hline
\end{tabular}

RFA-1 represents $100 \%$ of the recycled brick granule aggregate. RFA-2 represents $33.4 \%$ of the recycled brick granule aggregate replaced by concrete granules. RFA-3 represents $66.6 \%$ of the recycled brick granule aggregate replaced by concrete granules. RFA-4 represents $100 \%$ of the recycled brick granule aggregate replaced by concrete granules.

\subsection{Mix Proportions for the Recycled Aggregate}

In order to obtain continuously graded sand, the fine recycled aggregate and natural aggregate needed sieving with a series of sieves of different sizes to guarantee a maximum particle size of less than $4.75 \mathrm{~mm}$. In Table 1, the properties of the aggregates are shown in accordance with JGJ 52-2006 [25]. These indicate that the ratio of brick granules in the combination has the great impact on the properties of the recycled aggregate. The apparent density and bulk density of recycled aggregates added to the mixture constantly decline as the percentage of brick granule increased as the mud content and water absorption increased.

\subsection{Specimen Casting and Curing}

A concrete mixer with a volume of $30 \mathrm{~L}$ was used in this experiment. The materials were added in the same order-the sand was added first, followed by cement and lime powder. After the mixture was stirred homogeneously, recycled aggregate was stirred in, and later on, water was added and stirred for 3-5 min. After mixing for a while, the RAIW mixture was poured into the plastic test mold. The vibrator made the mixture dense and smooth, and then the mold was removed $24 \mathrm{~h}$ later. The specimens were prepared by curing with water within 7 days after removing the mold. Following curing outdoors for 28 days under natural conditions, the mechanical properties test was conducted after drying naturally.

\subsection{Load Equipment and Test Method}

The compressive strength test of the recycled aggregate infill wall materials (RAIW) was conducted in accordance with GB 50081-2002 [26]. The compressive strength was measured with a universal test machine with a loading rate of $4 \mathrm{kN} / \mathrm{s}$. The dimensions of each cubic sample used were $100 \times 100 \times 100\left(\mathrm{~mm}^{3}\right)$. The loading method of the flexural strength test is shown in Figure 1, and this was carried in the flexural test machine with a loading rate of $0.2 \mathrm{kN} / \mathrm{s}$. In this test, the size of the prism specimens used was $100 \times 100 \times 400\left(\mathrm{~mm}^{3}\right)$, and the span of the test section was $300 \mathrm{~mm}$. 

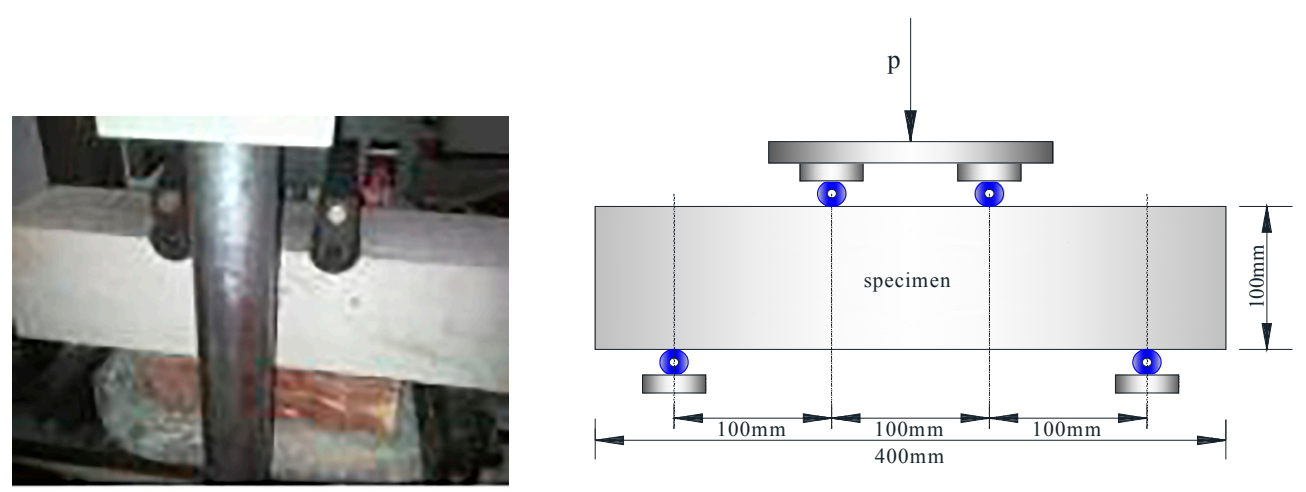

Figure 1. Loading setup of flexural test.

\subsection{Factors-Horizontal Selection}

In order to analyze the influence of mix proportion on the properties of the RAIW, the brick granule content, the water-cement ratio and replacement rate needed to be considered. A detailed combinations of the factors and levels is shown in Table 2.

Table 2. Factors and levels.

\begin{tabular}{cccccc}
\hline Level & Factor A (\%) & Factor B (\%) & Factor C (\%) & Factor D (\%) & Factor E (\%) \\
\hline Level 1 & 100 & 0.7 & $7: 1$ & 0 & 0 \\
Level 2 & 66.6 & 0.8 & $8: 1$ & 10 & 25 \\
Level 3 & 33.4 & 0.9 & $9: 1$ & 20 & 50 \\
Level 4 & 0.0 & 1.0 & $10: 1$ & 30 & 100 \\
\hline
\end{tabular}

Factor A: brick granule content; Factor B: water-cement ratio; Factor C: aggregate-cement ratio; Factor D: admixture of the lime powder; Factor E: replacement rate of the natural aggregate sand.

\subsection{Orthogonal Design}

In accordance with the orthogonal design of the combinations of all factor levels, a corresponding orthogonal design table $\left(L_{16}\left(4^{5}\right)\right)$ was obtained using the DOE method. Each group was designed based on the orthogonal design Table 3 according to the mass method (refer to JGJ 55-2011 [27]). The details are listed in Table 4.

Table 3. $L_{16}\left(4^{5}\right)$ Orthogonal design list.

\begin{tabular}{cccccc}
\hline Level/Factor & Factor A & Factor B & Factor C & Factor D & Factor E \\
\hline$L_{1}$ & 1 & 1 & 1 & 1 & 1 \\
$L_{2}$ & 1 & 2 & 2 & 2 & 2 \\
$L_{3}$ & 1 & 3 & 3 & 3 & 3 \\
$L_{4}$ & 1 & 4 & 4 & 4 & 4 \\
$L_{5}$ & 2 & 1 & 2 & 3 & 4 \\
$L_{6}$ & 2 & 2 & 1 & 4 & 3 \\
$L_{7}$ & 2 & 3 & 4 & 1 & 2 \\
$L_{8}$ & 2 & 4 & 3 & 2 & 1 \\
$L_{9}$ & 3 & 1 & 3 & 4 & 2 \\
$L_{10}$ & 3 & 2 & 4 & 3 & 1 \\
$L_{11}$ & 3 & 3 & 1 & 2 & 4 \\
$L_{12}$ & 3 & 4 & 2 & 1 & 3 \\
$L_{13}$ & 4 & 1 & 4 & 2 & 3 \\
$L_{14}$ & 4 & 2 & 3 & 1 & 4 \\
$L_{15}$ & 4 & 3 & 2 & 4 & 1 \\
$L_{16}$ & 4 & 4 & 1 & 3 & 2 \\
\hline
\end{tabular}


Table 4. Orthogonal test.

\begin{tabular}{|c|c|c|c|c|c|c|c|c|c|c|}
\hline \multirow{2}{*}{ Specimens } & \multicolumn{5}{|c|}{ Mix Proportions } & \multicolumn{5}{|c|}{ Component/kg } \\
\hline & Brick Granule/\% & Water-Cement Ratio & Aggregate-Cement Ratio & Lime Dosage/\% & Replacement Rate/\% & Water & Cement & Sand & Recycled & Lime \\
\hline$L_{1}$ & 100.0 & 0.7 & $7: 1$ & 0 & 0 & 4.3 & 6.2 & 43.4 & 0.0 & 0.0 \\
\hline$L_{2}$ & 100.0 & 0.8 & $8: 1$ & 10 & 25 & 4.4 & 5.0 & 33.0 & 11.0 & 0.6 \\
\hline$L_{3}$ & 100.0 & 0.9 & $9: 1$ & 20 & 50 & 4.5 & 4.0 & 22.5 & 22.5 & 0.9 \\
\hline$L_{4}$ & 100.0 & 1.0 & $10: 1$ & 30 & 100 & 4.5 & 3.1 & 0.0 & 45.0 & 1.4 \\
\hline$L_{5}$ & 0.0 & 0.7 & $8: 1$ & 20 & 100 & 3.9 & 4.5 & 0.0 & 45.0 & 1.1 \\
\hline$L_{6}$ & 0.0 & 0.8 & $7: 1$ & 30 & 50 & 4.9 & 4.3 & 21.4 & 21.4 & 1.8 \\
\hline$L_{7}$ & 0.0 & 0.9 & $10: 1$ & 0 & 25 & 4.1 & 4.5 & 11.3 & 11.3 & 0.0 \\
\hline$L_{8}$ & 0.0 & 1.0 & $9: 1$ & 10 & 0 & 4.9 & 4.4 & 0.0 & 0.0 & 0.5 \\
\hline$L_{10}$ & 66.6 & 0.8 & $10: 1$ & 20 & 0 & 3.7 & 3.7 & 0.0 & 0.0 & 0.9 \\
\hline$L_{11}$ & 66.6 & 0.9 & $7: 1$ & 10 & 100 & $5 . .4$ & 5.5 & 0.0 & 42.0 & 0.6 \\
\hline$L_{12}$ & 66.6 & 1.0 & $8: 1$ & 0 & 50 & 5.4 & 5.4 & 21.6 & 21.6 & 0.0 \\
\hline$L_{13}$ & 33.4 & 0.7 & $10: 1$ & 10 & 50 & 3.2 & 4.1 & 23.0 & 23.0 & 0.5 \\
\hline$L_{14}$ & 33.4 & 0.8 & $9: 1$ & 0 & 100 & 4.0 & 5.0 & 0.0 & 45.0 & 0.0 \\
\hline$L_{15}$ & 33.4 & 0.9 & $8: 1$ & 30 & 0 & 5.0 & 3.8 & 44.0 & 0.0 & 1.7 \\
\hline$L_{16}$ & 33.4 & 1.0 & $7: 1$ & 20 & 25 & 6.0 & 4.8 & 31.5 & 10.5 & 1.2 \\
\hline
\end{tabular}




\section{Results and Analysis}

\subsection{The Failure Process and Patterns of Specimens}

The failure process of the compressive test of the RAIW cube showed that with early loading, block surface cracking is not found. With an increase in load, the cracks appeared on the side surface of the block and then developed constantly. In the middle location of the height of the specimens, the cracks were vertical and developed upwards and downwards and turning towards the corner of the test block to the loading surface to form inverted "V"-shaped oblique cracks. As the load further increased, new cracks gradually developed on the inside, and the cracks appeared on the surface of the concrete and on the outer convex. The destroyed section of the specimens was shown in Figure 2, where the cement paste between the recycled fine aggregate fell off. It was observed from careful observation of the destruction of interface that typical failure modes of the RAIW occurred when the substrate was damaged causing the interface to fall off.
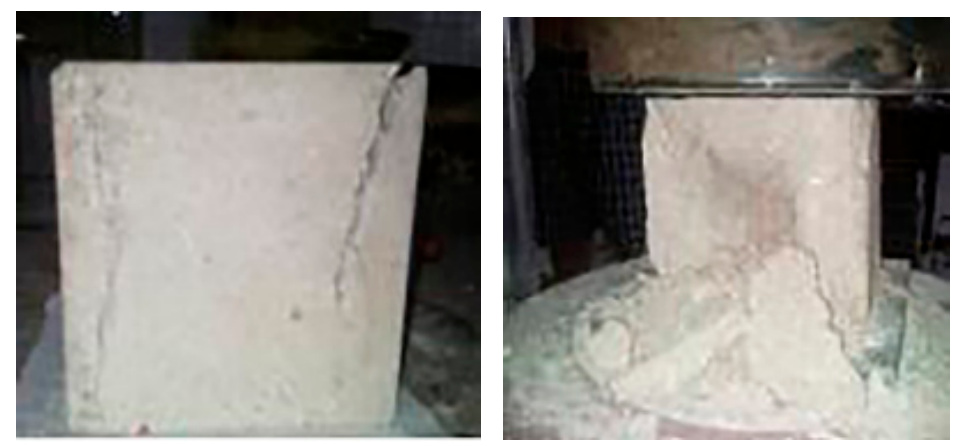

Figure 2. Failure modes of specimens after the compression test.

The section destroyed in the flexural strength test of the RAIW was the same as that in the compressive strength test cross-section, which shows the damaged substrate and interface fallen off. A detailed picture of the destroyed section is shown in Figure 3. In addition, it was also found that cracks on the RAIW were distributed between the two concentrated loading lines, and the direction of the cracks was vertical, which is perpendicular to the loading surface.
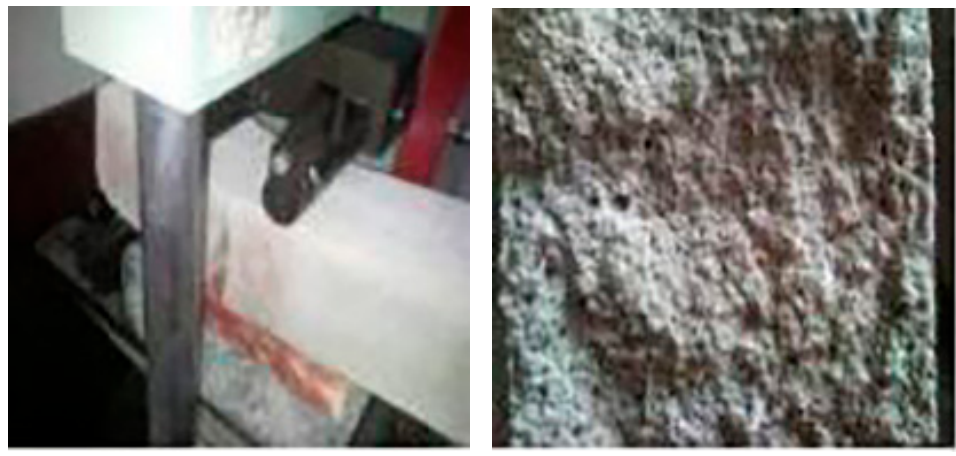

Figure 3. Failure modes of the specimens after the flexural test.

\subsection{Compressive Strength}

The failure loads at different aggregate replacement rates for each group of specimens were measured. Simultaneously, the compressive strength was calculated in accordance with standards GB/T 50081-2002 [26].

The compressive strength of each cubic specimen was measured, which is shown in Table 5. The impact factors of the specimens on the compressive strength intuitive analysis curve are given 
in Figure 4. From Figure 4, it can be seen the compressive strength of the RAIW had a significantly declining trend as the water-cement ratio increased after the $B_{2}$ point. In addition, the compressive strength decreased by $53.53 \%$ when the water-cement ratio increased from $B_{2}$ to $B_{4}$. In addition, as the aggregate-cement ratio and the lime mixture increased, the compressive strength also presented a decreasing trend, although the declining trend was relatively less than what caused by the water-cement ratio. What is more, the compressive strength of the RAIW slightly declined as the aggregate-cement ratio increased.

Table 6 shows the analysis of the range and variance of the compressive strength, from which it can be observed that the maximum variance in the water-cement ratio was 3.294, which is between $F_{0.05}$ and $F_{0.01}$. This shows that the impact of the water-cement ratio on the compressive strength is significant. In addition, the variance value of the aggregate-cement ratio was 2.938 , which is between $F_{0.1}$ and $F_{0.05}$. This implies that the impact of the aggregate-cement ratio on the RAIW is also significant, while the $F$ values of the other three factors were less than $F_{0.01}$, which suggests that their impacts are not significant. Through an analysis of the variance, it was also shown that the water-cement ratio is the primary factor influencing the compressive strength of the RAIW.

Table 5. Results of the compression test and the flexural test.

\begin{tabular}{|c|c|c|c|c|c|c|c|c|}
\hline \multirow{2}{*}{ Specimens } & \multirow{2}{*}{ Combination Order } & \multicolumn{3}{|c|}{ Results of Compression Test } & \multicolumn{3}{|c|}{ Results of Flexural Test } & \multirow{2}{*}{$f_{t} / f_{c u}$} \\
\hline & & $F c / k N$ & Section Size $/(\mathrm{mm} \times \mathrm{mm})$ & $f_{c u} / \mathrm{Mpa}$ & $F_{t} / \mathbf{k N}$ & Pressure Size $b l /(\mathrm{mm} \times \mathrm{mm})$ & $\overline{f_{t} / \mathrm{Mpa}}$ & \\
\hline$L_{1}$ & $\mathrm{~A}_{1} \mathrm{~B}_{1} \mathrm{C}_{1} \mathrm{D}_{1} \mathrm{E}_{1}$ & 106.7 & $98 \times 98$ & 10.1 & 9.5 & $99 \times 395$ & 2.4 & 0.238 \\
\hline$L_{3}$ & $\mathrm{~A}_{1} \mathrm{~B}_{3} \mathrm{C}_{3} \mathrm{D}_{3} \mathrm{E}_{3}$ & 35.2 & $98 \times 98$ & 3.3 & 5.1 & $100 \times 394$ & 1.3 & 0.394 \\
\hline$L_{4}$ & $\mathrm{~A}_{1} \mathrm{~B}_{4} \mathrm{C}_{4} \mathrm{D}_{4} \mathrm{E}_{4}$ & 18.0 & $98 \times 98$ & 1.7 & 2.0 & $100 \times 396$ & 0.5 & 0.294 \\
\hline$L_{5}$ & $\mathrm{~A}_{2} \mathrm{~B}_{1} \mathrm{C}_{2} \mathrm{D}_{3} \mathrm{E}_{4}$ & 14.5 & $98 \times 98$ & 1.8 & 2.8 & $98 \times 389$ & 0.7 & 0.389 \\
\hline$L_{6}$ & $\mathrm{~A}_{2} \mathrm{~B}_{2} \mathrm{C}_{1} \mathrm{D}_{4} \mathrm{E}_{3}$ & 79.7 & $98 \times 98$ & 7.6 & 7.1 & $99 \times 398$ & 1.8 & 0.237 \\
\hline$L_{9}$ & $\mathrm{~A}_{3} \mathrm{~B}_{1} \mathrm{C}_{3} \mathrm{D}_{4} \mathrm{E}_{2}$ & 33.3 & $99 \times 99$ & 3.2 & 4.2 & $100 \times 399$ & 1.1 & 0.344 \\
\hline$L_{10}$ & $\mathrm{~A}_{3} \mathrm{~B}_{2} \mathrm{C}_{4} \mathrm{D}_{3} \mathrm{E}_{1}$ & 46.4 & $98 \times 99$ & 4.4 & 4.8 & $98 \times 396$ & 1.2 & 0.273 \\
\hline$L_{11}$ & $\mathrm{~A}_{3} \mathrm{~B}_{3} \mathrm{C}_{1} \mathrm{D}_{2} \mathrm{E}_{4}$ & 49.0 & $98 \times 98$ & 4.7 & 4.1 & $99 \times 395$ & 1.1 & 0.234 \\
\hline$L_{12}$ & $\mathrm{~A}_{3} \mathrm{~B}_{4} \mathrm{C}_{2} \mathrm{D}_{1} \mathrm{E}_{3}$ & 14.5 & $97 \times 98$ & 1.8 & 2.4 & $100 \times 396$ & 0.6 & 0.333 \\
\hline$L_{13}$ & $\mathrm{~A}_{4} \mathrm{~B}_{1} \mathrm{C}_{4} \mathrm{D}_{2} \mathrm{E}_{3}$ & 31.7 & $98 \times 99$ & 3.0 & 3.4 & $100 \times 395$ & 0.9 & 0.300 \\
\hline$L_{14}$ & $\mathrm{~A}_{4} \mathrm{~B}_{2} \mathrm{C}_{3} \mathrm{D}_{1} \mathrm{E}_{4}$ & 92.7 & $99 \times 99$ & 8.8 & 8.7 & $99 \times 398$ & 2.2 & 0.250 \\
\hline
\end{tabular}

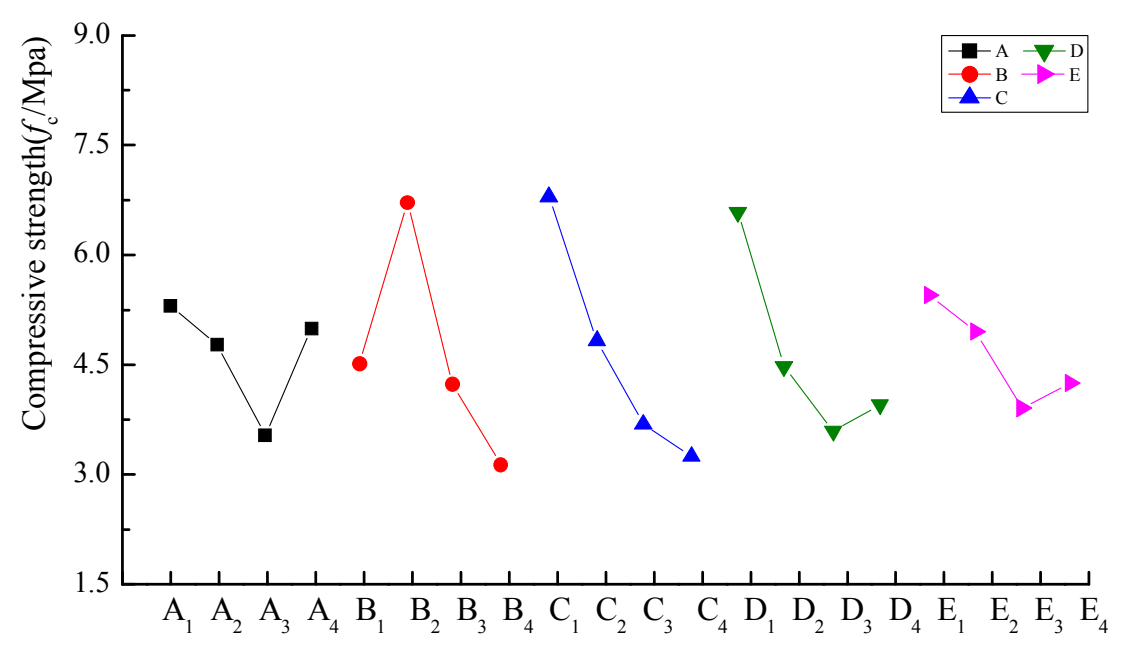

Figure 4. Intuitive analysis of the compressive strength. 
Table 6. Analysis of the factors influencing the compressive strength.

\begin{tabular}{cccccccccccc}
\hline \multirow{2}{*}{ Factor } & \multicolumn{4}{c}{ Level } & \multicolumn{1}{c}{ Results } \\
\cline { 2 - 12 } & $\mathbf{1}$ & $\mathbf{2}$ & $\mathbf{3}$ & $\mathbf{4}$ & $\boldsymbol{r}$ & $\boldsymbol{D f}$ & $\boldsymbol{F}$ & $\boldsymbol{F}_{\mathbf{0 . 1}}$ & $\boldsymbol{F}_{\mathbf{0 . 0 5}}$ & $\boldsymbol{F}_{\mathbf{0 . 0 1}}$ & Sig. \\
\hline A & 5.300 & 4.800 & 3.525 & 5.000 & 1.775 & 3 & 0.792 & 2.490 & 3.290 & 5.420 & - \\
B & 4.525 & 6.725 & 4.250 & 3.125 & 3.600 & 3 & 3.294 & 2.490 & 3.290 & 5.420 & $*$ \\
C & 6.825 & 4.850 & 3.700 & 3.250 & 3.575 & 3 & 2.938 & 2.490 & 3.290 & 5.420 & $\#$ \\
D & 6.600 & 4.475 & 3.600 & 3.950 & 3.000 & 3 & 2.342 & 2.490 & 3.290 & 5.420 & - \\
E & 5.475 & 4.975 & 3.925 & 4.250 & 1.550 & 3 & 0.636 & 2.490 & 3.290 & 5.420 & - \\
\hline
\end{tabular}

Symbol “*” represents significant impact, symbol "\#” represents significant secondary impact, symbol "-" represents not significant. The same symbols are used below.

\subsection{Flexural Strength}

The failure load of the RAIW specimens at different replacement levels was obtained, and the flexural strength of the RAIW was calculated with standards GB/T 50081-2002 [26]. Due to using $100 \times 100 \times 400\left(\mathrm{~mm}^{3}\right)$ non-standard specimens made by the RAIW, the nominal flexural strength was multiplied by a conversion factor of 0.85 , in accordance with the relevant Chinese standard [26].

Details are shown in Table 5. The flexural strength of each specimen measured can be observed. Table 7 gives the analysis of the range and variance data of specimens, from which the primary and secondary impact factors on the flexural strength and their significance can be obtained. The results indicate that among the test factor levels, the water-cement ratio is the major factor that affects the flexural strength, (with the an increase in the water-cement ratio from $\mathrm{B}_{2}$ to $\mathrm{B}_{4}$, the flexural strength decreased by $47.76 \%$ ), followed by the mixed amounts of aggregate cement and lime powder. However, other two factors showed a tendency to fluctuate. Thus, there no significant effects from the regenerated brick granule volume and the replacement rate were observed, indicating their impacts on the compressive strength. Therefore, it can be considered that strict control of the water-cement ratio is important for the mechanical properties of RAIW.

The intuitive analysis curve of the factors impacting the flexural strength can be observed in Figure 5, from which similar tendencies can be observed for the flexural strength and the compressive strength of RAIW. With increases in the water-cement ratio, aggregate-cement ratio and the lime powder content, the mechanical properties showed a declining trend, and the order of influencing factors was revealed as the following: the water-cement ratio, the aggregate-cement ratio, lime powder, the aggregate replacement rate and the brick granule content in the aggregate.

Table 7. Analysis of influencing factors on flexural strength.

\begin{tabular}{cccccccccccc}
\hline \multirow{2}{*}{ Factor } & \multicolumn{9}{c}{ Level } & \multicolumn{1}{c}{ Results } \\
\cline { 2 - 13 } & $\mathbf{1}$ & $\mathbf{2}$ & $\mathbf{3}$ & $\mathbf{4}$ & $\boldsymbol{r}$ & $\boldsymbol{D} \boldsymbol{f}$ & $\boldsymbol{F}$ & $\boldsymbol{F}_{\mathbf{0 . 1}}$ & $\boldsymbol{F}_{\mathbf{0 . 0 5}}$ & $\boldsymbol{F}_{\mathbf{0 . 0 1}}$ & Sig. \\
\hline A & 1.425 & 1.275 & 1.000 & 1.200 & 0.425 & 3 & 0.854 & 2.490 & 3.290 & 5.420 & - \\
B & 1.275 & 1.675 & 1.150 & 0.800 & 0.875 & 3 & 3.564 & 2.490 & 3.290 & 5.420 & $*$ \\
C & 1.550 & 0.900 & 1.450 & 1.000 & 0.650 & 3 & 2.848 & 2.490 & 3.290 & 5.420 & $\#$ \\
D & 1.650 & 1.175 & 1.025 & 1.050 & 0.625 & 3 & 2.312 & 2.490 & 3.290 & 5.420 & - \\
E & 1.400 & 1.225 & 1.150 & 1.125 & 0.275 & 3 & 0.422 & 2.490 & 3.290 & 5.420 & - \\
\hline
\end{tabular}




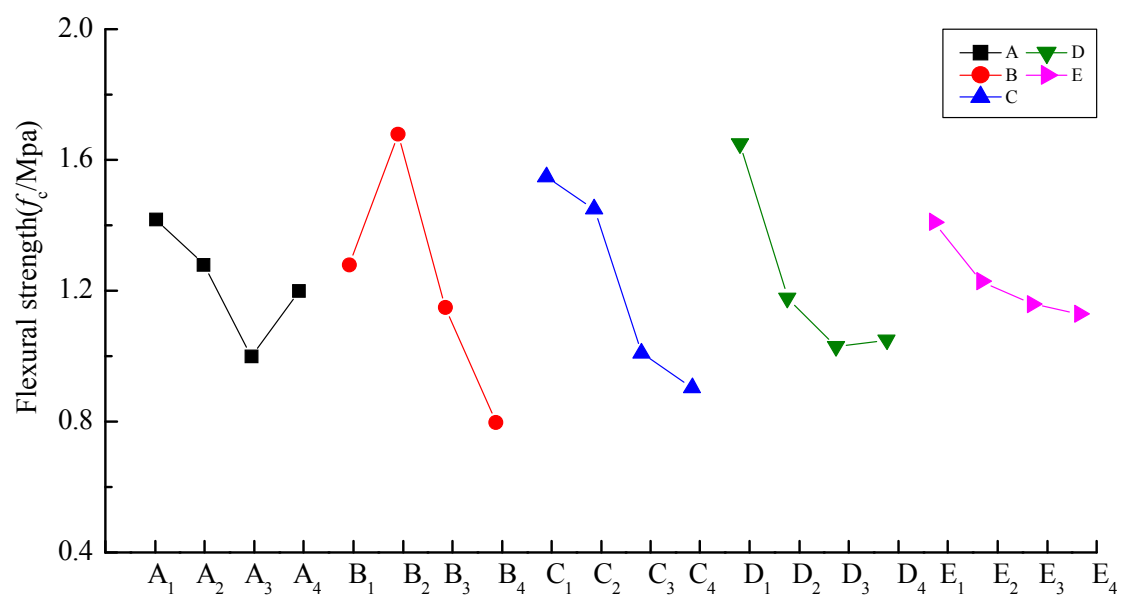

Figure 5. Intuitive analysis of flexural strength.

\subsection{Flexural-Compressive Ratio of the RAIW}

The compressive strength of the each group of cubic specimens of RAIW ranged from 1.8 to 10.1 Mpa, and the flexural strength ranged from 0.5 to $2.4 \mathrm{Mpa}$. The relative values of the flexural-compressive ratio for each specimen can be seen in Table 5 , in which the values range from 0.184 to 0.389 . The range of the flexural-compressive ratio is given in Table 8. It can be observed that the factor most affecting the flexural-compressive ratio of the RAIW is the aggregate-cement ratio, which attained a significant level of influence on the flexural-compressive ratio of the RAIW, while the other factors were insignificant.

Table 8. Analysis of the influencing factors on the flexural-compressive ratio.

\begin{tabular}{cccccccccccc}
\hline \multirow{2}{*}{ Factor } & \multicolumn{1}{c}{ Level } & \multicolumn{1}{c}{ Results } \\
\cline { 2 - 13 } & $\mathbf{1}$ & $\mathbf{2}$ & $\mathbf{3}$ & $\mathbf{4}$ & $\boldsymbol{r}$ & $\boldsymbol{D f}$ & $\boldsymbol{F}$ & $\boldsymbol{F}_{\mathbf{0 . 1}}$ & $\boldsymbol{F}_{\mathbf{0 . 0 5}}$ & $\boldsymbol{F}_{\mathbf{0 . 0 1}}$ & Sig. \\
\hline A & 0.293 & 0.291 & 0.296 & 0.244 & 0.052 & 3 & 1.346 & 2.490 & 3.290 & 5.420 & - \\
B & 0.318 & 0.252 & 0.279 & 0.276 & 0.066 & 3 & 1.730 & 2.490 & 3.290 & 5.420 & - \\
C & 0.223 & 0.302 & 0.320 & 0.278 & 0.097 & 3 & 4.038 & 2.490 & 3.290 & 5.420 & $*$ \\
D & 0.267 & 0.268 & 0.310 & 0.279 & 0.043 & 3 & 0.962 & 2.490 & 3.290 & 5.420 & - \\
E & 0.261 & 0.255 & 0.316 & 0.292 & 0.061 & 3 & 1.924 & 2.490 & 3.290 & 5.420 & - \\
\hline
\end{tabular}

\section{Strength Regression Analysis}

In order to analyze the relationship between the mechanical properties of RAIW and the five influencing factors, a regression analysis was completed in this study. The hypothesis was that a linear relationship would exist between the mechanical property indexes (the compressive strength, flexural strength, the flexural-compressive ratio) and the five influencing factors (brick granule content, water-cement ratio, aggregate-cement ratio, proportions of mixtures, and the replacement rate). The linear regression model was calculated as follows:

$$
y=a_{1} x_{1}+a_{2} x_{2}+a_{3} x_{3}+a_{4} x_{4}+a_{5} x_{5}+e
$$

where " $y$ " is the compressive strength, flexural strength or flexural-compressive ratio; " $a_{i}$ " $(i=1,2,3$, $4,5)$ are the regression coefficients; " $x_{1}$ " is the brick powder content; " $x_{2}$ " is the water-cement ratio; " $x_{3}$ " is the aggregate-cement ratio; " $x_{4}$ " is the proportions of the mixtures; " $x_{5}$ " is the replacement of aggregate ratio; and " $e$ " is the test error, respectively.

By substituting the data into the regression model in Table 5, the least squares estimation was obtained. The regression equation is given below. 
Compressive strength calculation formula:

$$
\begin{gathered}
y=0.166 x_{1}-3.7159 x_{2}+78.7234 x_{3}-8.3028 x_{4}-1.1265 x_{5}+0.188 \\
R=0.8765, n=16, F_{I}=15.6068 .
\end{gathered}
$$

Flexural strength calculation formula:

$$
\begin{gathered}
y=0.149 x_{1}-0.6555 x_{2}+16.9767 x_{3}-1.7216 x_{4}-0.1905 x_{5}+0.041 \\
R=0.8893, n=16, F_{I}=17.6770 .
\end{gathered}
$$

Flexural-compressive ratio calculation formula:

$$
\begin{gathered}
y=0.0322 x_{1}+0.1875 x_{2}+0.4903 x_{3}+0.1296 x_{4}+0.0530 x_{5}-0.0039 \\
R=0.9470, n=16, F_{I}=39.2829 .
\end{gathered}
$$

In the equations all, " $R$ " is the corresponding coefficient; " $n$ " is the degrees of freedom; and " $F_{I}$ " is the variance in the regression equation.

In this study, 96 specimens, of 16 combinations in total, were prepared for the compressive strength and flexural strength tests. Since the number of variables was 6 , the number of degrees of freedom was 10, and the confidence level was $1 \%$. The corresponding coefficient of 0.708 can be obtained from the relevant table. As the result of $R=0.8765(0.8893 / 0.9470)>0.708$, the hypothesis of the linear model was found to be reasonable, and the regression equation obtained with this method is meaningful. In addition, from the variance in the regression equation, $F_{I}=15.6068(17.6770 / 39.2829)>$ $F_{0.1}(10,5)=2.52$, it can be observed that the regression equation obtained by the linear assumption has great significance. By putting the mix proportions of each group into the regression equation (as

\begin{tabular}{|c|c|c|c|c|c|c|c|c|c|c|c|c|c|c|c|c|c|}
\hline \multirow{2}{*}{\multicolumn{2}{|c|}{ Results Analysis }} & \multicolumn{16}{|c|}{ Specimens } \\
\hline & & $L_{1}$ & $L_{2}$ & $L_{3}$ & $L_{4}$ & $L_{5}$ & $L_{6}$ & $L_{7}$ & $L_{8}$ & $L_{9}$ & $L_{10}$ & $L_{11}$ & $L_{12}$ & $L_{13}$ & $L_{14}$ & $L_{15}$ & $L_{16}$ \\
\hline \multirow{3}{*}{$f_{c u}$} & Measured & 10.1 & 6.10 & 3.30 & 1.70 & 1.80 & 7.60 & 5.70 & 4.10 & 3.20 & 4.40 & 4.70 & 1.80 & 3.00 & 8.80 & 3.30 & 4.90 \\
\hline & Theoretical & 8.81 & 5.92 & 3.34 & 0.71 & 3.40 & 6.22 & 4.25 & 4.25 & 3.48 & 3.35 & 5.67 & 3.21 & 3.93 & 7.10 & 4.06 & 5.64 \\
\hline & Deviation & 1.2 & 0.18 & 0.04 & 0.99 & 1.60 & 1.38 & 1.55 & 0.10 & 0.28 & 1.05 & 0.97 & 1.41 & 0.93 & 1.70 & 0.76 & 0.74 \\
\hline \multirow{3}{*}{$f_{t}$} & Measured & 2.40 & 1.50 & 1.30 & 0.50 & 0.70 & 1.80 & 1.40 & 1.20 & 1.10 & 1.20 & 1.10 & 0.60 & 0.90 & 2.20 & 0.80 & 0.90 \\
\hline & Theoretical & 2.11 & 1.52 & 1.00 & 0.48 & 1.13 & 1.29 & 1.06 & 1.06 & 0.96 & 1.57 & 1.47 & 0.92 & 1.02 & 2.23 & 1.06 & 1.43 \\
\hline & Deviation & 0.29 & 0.02 & 0.30 & 0.02 & 0.43 & 0.51 & 0.34 & 0.14 & 0.14 & 0.37 & 0.37 & 0.32 & 0.12 & 0.03 & 0.26 & 0.53 \\
\hline \multirow{3}{*}{$f_{t} / f_{c u}$} & Measured & 0.24 & 0.25 & 0.39 & 0.29 & 0.39 & 0.24 & 0.25 & 0.29 & 0.34 & 0.27 & 0.23 & 0.33 & 0.30 & 0.25 & 0.24 & 0.18 \\
\hline & Theoretical & 0.23 & 0.26 & 0.31 & 0.27 & 0.36 & 0.28 & 0.23 & 0.25 & 0.32 & 0.24 & 0.26 & 0.29 & 0.23 & 0.26 & 0.27 & 0.24 \\
\hline & deviation & 0.01 & 0.01 & 0.08 & 0.02 & 0.03 & 0.04 & 0.02 & 0.04 & 0.02 & 0.03 & 0.03 & 0.04 & 0.07 & 0.01 & 0.03 & 0.06 \\
\hline
\end{tabular}
shown in Table 9), the theoretical calculation can be obtained. From Table 9 and Figure 6, it can be observed that the differences between the theoretical and measured values of the compressive strength, flexural strength and flexural-compressive ratio were, respectively, 0.1-1.7, 0.02-0.53 and 0.01-0.08; which shows that the fitting equation from the linear supposition is reasonable.

Table 9. Measured values and theoretical values of compressive strength and flexural strength. 


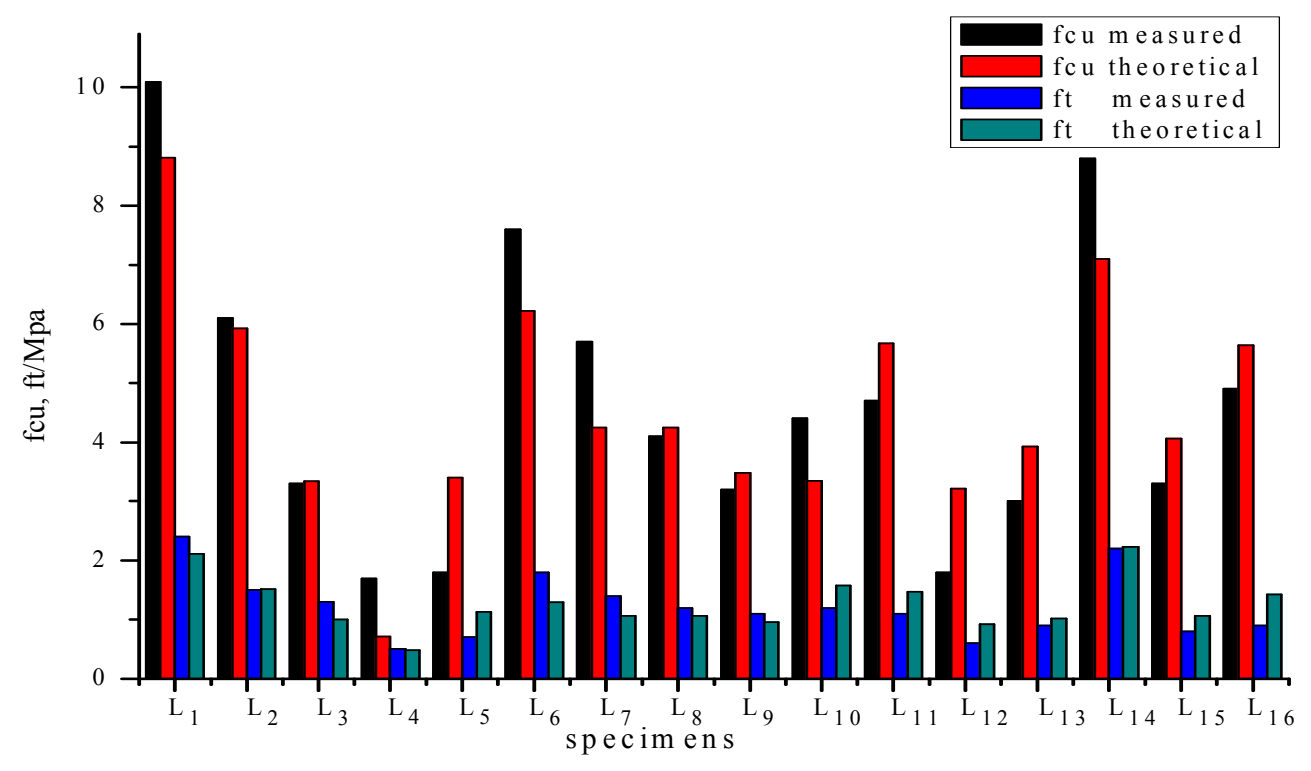

Figure 6. Intuitive analysis of the measured and theoretical strengths.

\section{Discussion on the Microscopic Mechanisms of RAIW Destruction}

Compared to the natural aggregate infill wall materials (NAIW), recycled aggregate infill wall (RAIW) materials possess greater nonuniformity, more complex internal structures, and higher levels of randomness. However, the interfacial transition zone between the cement and recycled aggregate is weaker. Improving the composition, structure and properties of the interfacial transition zone is one of the methods used to enhance and improve the mechanical properties of RAIW. Changes in the water-cement ratio, amount of recycled aggregate, aggregate-cement ratio, and amount of additives have important effects on the transition layer's structure.

(1) For the RAIW, because of the porosity and high water absorption characteristics of the recycled aggregates relative to those of natural aggregates, a large part of the moisture mixed into cement-based materials is absorbed by the porosity of the recycled aggregates and tiny particles, forming the internal free water. The remaining water penetrates into the internal part of the cement-based materials, acting as a binder and participating in hydration reactions. In the case of a low water-cement ratio, most of the moisture is absorbed by the pores of the recycled aggregate and tiny particles, and only a little water penetrates into the internal part of the cement-based materials to participate in the hydration reaction, resulting in an insufficient number of hydrated cement reactions. Most of the cement cannot form the C-S-H cementitious system; thus, the interfacial aggregate connection is weak-that is to say, the mechanical properties of the RAIW are weak. In the case of a high water-cement ratio, a lot of moisture that is not absorbed by the pores of recycled aggregate and the tiny particles penetrates into the internal part of the cement-based materials. These moisture levels exceed the amount of the water required for the hydration reaction. Although the hydration of the cement is conducted sufficiently, the remaining moisture causes the concentration of the hydration production (cementitious system) to decrease. In addition, has also been shown that the use of too much water increases the heat in the hydration process, resulting in increased porosity of the interfacial aggregate connection, thus decreasing the mechanical properties of the RAIW. The water-cement ratio curve can be seen in Figures 4 and 5 . When the water-cement ratio was less than 0.8 , the moisture that penetrated to the hydration cement-based materials did not reach the standard of bond water. Therefore, the mechanical properties were lower than when the water cement ratio was 0.8 . When the water-cement ratio was more than 0.8 , the use of excessive water caused the concentration of the hydration production to decrease, and a lot of heat of hydration was released; eventually, the mechanical properties of the RAIW degenerated. 
(2) Since the recycled aggregate was made with the waste concrete and abandoned brick block, a large number of micro-cracks and initial damage between the interfacial of the old structure was present. Moreover, recycled mixtures contain lots of tiny particles; these tiny particles made the interfacial between the old and the new parts of the RAIW less thin, and a serious drying shrinkage effect appeared after the formation of the RAIW forming, leading to the strength of RAIW declining further. It can be summarized that the mechanical properties of RAIW decrease as the aggregate-cement ratio and the recycled aggregate replacement rate increase. The aggregate-cement ratio and aggregate replacement rate curve are shown in Figures 4 and 5, respectively. When aggregate-cement ratio and aggregate replacement rate increased, the proportion of the recycled aggregate contained in the RAIW also increased. Simultaneously, the proportion of micro-particles taken in the cement-based materials by the recycled aggregate also increased; a large number of broken damage micro-cracks existed in these tiny particles. It is easy for a large number of tiny particles existed in cement-based materials to cause the RAIW to present a large dry shrinkage deformation, thus resulting in the degeneration of its mechanical properties.

(3) The lime admixture hydration process produces large amounts of $\mathrm{Ca}(\mathrm{OH})_{2}$, and a large amount of $\mathrm{Ca}(\mathrm{OH})_{2}$ was arranged in the recycled aggregate and cement contact interface. The $\mathrm{Ca}(\mathrm{OH})_{2}$ enrichment caused almost no cementitious system to exist in the contact zone. Thus, the bond strength of the interface reduced and accordingly, the mechanical properties of the RAIW declined. The lime dosage curve is shown in Figures 4 and 5. A the lime dosage content of the cement-based materials increased, enriched $\mathrm{Ca}(\mathrm{OH})_{2}$ was present in the contact interface of recycled aggregate and hardened cement paste. So, the interface had a thin zone thin, and stress was easily generated in this zone under the influence of force, destroying the RAIW along the interface.

\section{Conclusions}

(1) The brick granule content in RAIW have great effect on its performance. As a large quantity of tiny particles are contained in brick powder, the apparent density and bulk density of recycled aggregate constantly decreases as the brick powder content (brick-concrete ratio) increases, while the mud content and water absorption increase.

(2) For RAIW, the cross-section failure mode of the flexural test is similar to those of the compressive strength test, in which the substrate broke and the interface fell off. In addition, the failure mode of the compressive test presented inverted ' $V$ '-shaped oblique cracks, while the flexural strength test presented a longitudinal crack perpendicular to the loading surface.

(3) The order of influencing factors on RAIW is as follows: the water-cement ratio, the aggregate-cement ratio, the lime powder content, the brick granule content in the aggregate, the replacement rate.

(4) The water-cement ratio is the primary factor that influences the compressive strength, followed by the aggregate-cement ratio and the lime content. While the replacement ratio and the brick granule contained in the aggregate presented a wave tendency, this effect was not significant. The same rule was found for the analysis of variance and range for the flexural strength.

(5) The water-cement ratio at level of 0.7-0.8 was especially effective for improving the mechanical properties of RAIW in this experiment.

(6) The flexural-compressive ratio of RAIW ranged from 0.184 to 0.398 . The analysis of the variance and range indicated that the aggregate-cement ratio has the greatest impact on the flexural strength of RAIW.

(7) It was found that a good linear relationship exists between the mechanical properties of RAIW and the five factors examined in this experiment: brick granule content, the water-cement ratio, the aggregate-cement ratio, the lime content of the mixtures and the replacement rate. The proposed strength calculation formula presented better scientificity, which can provide a reference and can be applied in the relevant studies. 
Author Contributions: Z.C. conceived the experiments, J.F. designed the experiments and wrote the initial draft of the manuscript. Z.C., Y.Z. and J.C. analyzed the data and wrote the final manuscript.

Acknowledgments: This paper forms part of the research supported by the National Natural Science Foundation of PR China (grant 51578163), the project of Natural Science Research Foundation of Guangxi Province (grants 2012GXNSFAA053203 and 2013GXNSFDA019025), and the Key project of Polytechnic and Science Experimental Center of Guangxi Province (grant LGZX201102). The authors are grateful for the above supporters.

Conflicts of Interest: The authors declare no conflict of interest.

\section{References}

1. Lu, W.; Webster, C.J.; Peng, Y.; Chen, X.; Zhang, X. Estimating and calibrating the amount of building-related construction and demolition waste in urban China. Int. J. Constr. Manag. 2017, 17, 13-14. [CrossRef]

2. Poon, C.S.; Kou, S.C.; Lam, L. Use of recycled aggregates in molded concrete bricks and blocks. Constr. Build. Mater. 2002, 16, 281-289. [CrossRef]

3. Poon, C.S.; Shui, Z.H.; Lam, L.; Fok, H.; Kou, S.C. Influence of moisture state of natural and recycled aggregates on the slump and compressive strength of concrete. Cem. Concr. Res. 2004, 34, 31-36. [CrossRef]

4. Etxeberria, M.; Vazquez, E.; Mari, A.; Barra, M. Influence of amount of recycled coarse aggregates and production process on properties of recycled aggregate concrete. Cem. Concr. Res. 2007, 37, 735-742. [CrossRef]

5. Novakova, I.; Mikulica, K. Properties of concrete with partial replacement of natural aggregate by recycled concrete aggregates from precast production. Procedia Eng. 2016, 151, 360-367. [CrossRef]

6. Wagih, A.M.; El-Karmoty, H.Z.; Ebid, M.; Okba, S.H. Recycled construction and demolition concrete waste as aggregate for structural concrete. HBRC J. 2013, 9, 193-200. [CrossRef]

7. Nepomuceno, M.C.; Isidoro, R.A.; Catarino, J.P. Mechanical performance evaluation of concrete made with recycled ceramic coarse aggregates from industrial brick waste. Constr. Build. Mater. 2018, 165, $284-294$. [CrossRef]

8. Debieb, F.; Kenai, S. The use of coarse and fine crushed bricks as aggregate in concrete. Constr. Build. Mater. 2008, 22, 886-893. [CrossRef]

9. Ryu, J.S. Improvement on strength and impermeability of recycled concrete made from crushed concrete coarse aggregate. J. Mater. Sci. Lett. 2002, 21, 1565-1567. [CrossRef]

10. Duan, Z.H.; Poon, C.S. Properties of recycled aggregate concrete made with recycled made with recycled aggregates with different amounts of old adhered mortars. Mater. Des. 2014, 58, 19-29. [CrossRef]

11. Del Bosque, I.S.; Zhu, W.; Howind, T.; Matías, A.; de Rojas, M.S.; Medina, C. Properties of interfacial transition zones (ITZs) in concrete containing recycled mixed aggregate. Cem. Concr. Compos. 2017, 81, $25-34$. [CrossRef]

12. Shahidan, S.; Azmi, M.A.M.; Kupusamy, K.; Zuki, S.S.M.; Ali, N. Utilizing Construction and Demolition (C\&D) Waste as Recycled Aggregates (RA) in Concrete. Procedia Eng. 2017, 174, 1028-1035.

13. Letelier, V.; Tarela, E.; Munoz, P.; Moriconi, G. Combined effects of recycled hydrated cement and recycled aggregates on the mechanical properties of concrete. Constr. Build. Mater. 2017, 132, 365-375. [CrossRef]

14. Cachim, P.B. Mechanical properties of brick aggregate concrete. Constr. Build. Mater. 2009, 23, $1292-1297$. [CrossRef]

15. González, J.S.; Gayarre, F.L.; Pérez, C.L.C.; Ros, P.S.; López, M.A.S. Influence of recycled brick aggregates on properties of structural concrete for manufacturing precast prestressed beams. Constr. Build. Mater. 2017, 149, 507-514. [CrossRef]

16. Poon, C.S.; Kou, S.C.; Wan, H.W.; Etxeberria, M. Properties of concrete blocks prepared with low grade recycled aggregates. Waste Manag. 2009, 29, 2369-2377. [CrossRef] [PubMed]

17. Bui, N.K.; Satomi, T. Hiroshi Takahashi. Improvement of mechanical properties of recycled aggregate concrete basing on a new combination method between recycled aggregate and natural aggregate. Constr. Build. Mater. 2017, 148, 376-385. [CrossRef]

18. Katz, A. Properties of made with recycled aggregate from partially hydrated old concrete. Cem. Concr. Res. 2003, 33, 703-711. [CrossRef]

19. Xiao, Z.; Ling, T.C.; Kou, S.C.; Wang, Q.; Poon, C.S. Use of wastes derived from earthquakes for the production of concrete masonry partition wall blocks. Waste Manag. 2011, 31, 1859-1866. [CrossRef] [PubMed] 
20. Poon, C.S.; Chan, D. Effects of contaminants on the properties of concrete paving blocks prepared with recycled concrete agregates. Constr. Build. Mater. 2007, 21, 164-175. [CrossRef]

21. Tahar, Z.; Ngo, T.T.; Kadri, E.; Bouvet, A.; Debieb, F.; Aggoun, S. Effect of cement and admixture on the utilization of recycled aggregates in concrete. Constr. Build. Mater. 2017, 149, 91-102. [CrossRef]

22. Paul, S.C.; Babafemi, A.J.; Anggrini, V.; Rahman, M.M. Properties of Normal and Recycled Brick Aggregates for Production of Medium Range (25-30 Mpa). Struct. Strength Concr. Build. 2018, 8, 72.

23. Bravo, M.; de Brito, J.; Pontes, J.; Evangelista, L. Durability performance of concrete with recycled aggregates from construction and demolition waste plants. Constr. Build. Mater. 2015, 77, 357-369. [CrossRef]

24. Paul, S.C.; van Zijl, G.P. Mechanical and durability properties of recycled concrete aggregate for normal strength structural concrete. Int. J. Sustain. Constr. Eng. Technol. 2013, 4, 89-103.

25. JGJ52-2006, Standard for Technical Requirements and Test Method of Sand and Crushed Stone (or Gravel) for Ordinary Concrete, China; Architecture \& Building Press: Beijing, China, 2006. (In Chinese)

26. GB50081-2002, Standard for Test Method of Mechanical Properties on Ordinary Concrete, China; Architecture \& Building Press: Beijing, China, 2003. (In Chinese)

27. JGJ 55-2011, Specification for Mix Proportion Design of Ordinary Concrete, China; Architecture \& Building Press: Beijing, China, 2011. (In Chinese)

(C) 2018 by the authors. Licensee MDPI, Basel, Switzerland. This article is an open access article distributed under the terms and conditions of the Creative Commons Attribution (CC BY) license (http://creativecommons.org/licenses/by/4.0/). 